\title{
Dissociable Hormonal, Cognitive and Mood Responses to Neuroendocrine Challenge: Evidence for Receptor-Specific Serotonergic Dysregulation in Depressed Mood
}

W. J. Riedel, Ph.D., T. Klaassen, M.D., E. Griez, M.D., Ph.D., A. Honig, M.D., Ph.D., P.P.C.A. Menheere, Ph.D., and H.M. van Praag, M.D., Ph.D.

Fifteen patients with major depression, dysthymia, or anxiety disorder with depressed mood (DSM-IV diagnoses) and 16 controls received single oral doses of $0.5 \mathrm{mg} / \mathrm{kg}$ metachlorophenylpiperazine (m-CPP), a 5-HT $2 \mathrm{C}$ agonist, and $10 \mathrm{mg}$ ipsapirone, a 5-HT $\mathrm{T}_{1 \mathrm{~A}}$ agonist, according to double-blind, placebo-controlled, cross-over design. The groups' levels of cortisol, adrenocorticotrophic hormone (ACTH) and prolactin did not differ at baseline. Both 5-HT agonists significantly elevated cortisol, ACTH, and prolactin. The cortisol response to ipsapirone was significantly blunted in major depression and dysthymia patients. Neuroendocrine responses to $m-C P P$ did not differ between groups, but m-CPP selectively increased profile of mood states (POMS) depression and tenseness scores in patients. No effects of ipsapirone on mood were found. However, ipsapirone impaired memory performance in controls, but tended to improve memory performance in patients. The results support the evidence for both hypothalamic and possibly hippocampal 5- $\mathrm{HT}_{1 \mathrm{~A}}$ receptor desensitisation and non-hypothalamic, 5- $\mathrm{HT}_{2 \mathrm{C}}$ receptor sensitisation, probably fronto-cortical, in patients with major depression and dysthymia.

[Neuropsychopharmacology 26:358-367, 2002] (C) 2002 American College of Neuropsychopharmacology. Published by Elsevier Science Inc.
KEY WORDS: Neuroendocrine; Prolactin; Cortisol; ACTH; Serotonin; Depression; Memory

From the Brain and Behaviour Institute, Departments of Psychiatry and Neuropsychology (WJR, TK, EG, AH, HMvP), and Clinical Chemistry (PPCAM), University Hospital, Maastricht, The Netherlands

Address correspondence to: Dr. W.J. Riedel, Experimental Psychopharmacology Unit, Department of Psychiatry and Neuropsychology, Universiteit Maastricht P.O. Box 6166200 MD Maastricht, The Netherlands, Tel.: + 3143 3881027, Fax: + 3143 3884092, E-mail: Wim.Riedel@Np.UniMaas.NL

Received March 23, 2001; revised July 16, 2001; accepted August 16, 2001.

Online publication: $8 / 22 / 01$ at www.acnp.org/citations/ Npp082201168
Serotonergic abnormalities have been reported in various psychiatric disorders such as depression, anxiety, sleep disorders and schizophrenia. Neurotransmission abnormalities may differ according to the specific receptor subtypes involved and are expressed through biological markers such as elevated levels or exaggerated responses of pituitary hormones to selective receptor agonists (Maes and Meltzer 1995). It has been hypothesized that depressed mood is accompanied by: (1) downregulation of postsynaptic 5- $\mathrm{HT}_{1 \mathrm{~A}}$ receptors; (2) upregulation of 5- $\mathrm{HT}_{2 \mathrm{~A} / 2 \mathrm{C}}$ receptors (Maes and Meltzer 1995; Van Praag 1996).

The sensitivity of serotonergic receptors in the brain is considered to be one of the measures of the integrity of the 5-HT system. Neuroendocrine tests are based on 
the assumption that the 5-HT system exhibits an excitatory influence on the release of cortisol, ACTH, and prolactin (Yatham and Steiner 1993). Neuroendocrine responses to 5-HT agonists are an indication of postsynaptic receptor sensitivity, with relatively high hormonal responses being indicative of receptor hypersensitivity while relatively low hormonal responses suggest receptor hyposensitivity.

Meta-chlorophenylpiperazine (m-CPP), a full agonist of 5-HT receptors, was initially thought to be equipotent at all 5-HT receptor subtypes (Hamik and Peroutka 1989), but later studies describe a relatively high affinity of $\mathrm{m}-\mathrm{CPP}$ for postsynaptic $5-\mathrm{HT}_{2 \mathrm{C}}$ and $5-\mathrm{HT}_{3}$ receptors (Glennon et al. 1989; Hoyer 1988). Earlier research using $\mathrm{m}-\mathrm{CPP}$ challenges suggests that hypersensitivity of postsynaptic $5-\mathrm{HT}_{2 \mathrm{C}}$ receptors is associated with high levels of anxiety (Kahn et al. 1988a,b, 1991). Several authors provided evidence for $5-\mathrm{HT}_{2 \mathrm{~A} / 2 \mathrm{C}}$ upregulation in depression by means of neuroendocrine challenge with 5-HTP (Maes et al. 1995; Meltzer et al. 1984).

Ipsapirone, a partial agonist at 5-HT receptors, exhibits a relatively high affinity for both pre- and postsynaptic $5-\mathrm{HT}_{1 \mathrm{~A}}$ receptors and negligible affinity for the $5-\mathrm{HT}_{1 \mathrm{D}}, 5-\mathrm{HT}_{2}$ and $5-\mathrm{HT}_{3}$ subtypes (Peroutka 1988). Ipsapirone was originally developed as an antianxiety agent but also has anti-aggressive effects in rodents (De Vry 1995). In humans, blunted responses of cortisol to ipsapirone (a partial 5- $\mathrm{HT}_{1 \mathrm{~A}}$ receptor agonist) were found in patients with major depression (Lesch et al. 1990; Meltzer and Maes 1995).

Although blunted hormonal responses to $5-\mathrm{HT}_{1 \mathrm{~A}}$ agonists in patients with affective disorders have been shown before, attempts to compare the specificity of hormonal responses to $5-\mathrm{HT}_{1 \mathrm{~A}}$ and $5-\mathrm{HT}_{2 \mathrm{C}}$ challenges within the same group are surprisingly rare. Broocks et al. (Broocks et al. 1999) compared neuroendocrine challenge in marathon runners and controls and showed that a blunted cortisol response to $\mathrm{m}-\mathrm{CPP} 0.4 \mathrm{mg} / \mathrm{kg}$, but not to ipsapirone $0.3 \mathrm{mg} / \mathrm{kg}$, differentiated the marathon runners from controls. Broocks et al. (2000) also reported a study of neuroendocrine challenge with $\mathrm{m}$-CPP and ipsapirone in groups of patients with panic disorder and/ or agoraphobia and controls. They report tendencies toward an increased sensitivity of central $5-\mathrm{HT}_{2 \mathrm{C}}$ receptors and a decreased responsiveness of $5-\mathrm{HT}_{1 \mathrm{~A}}$ receptors in patients (Broocks et al. 2000). In order to further study the associations of altered 5-HT receptor sensitivities in depressed mood, we wanted to determine whether both the sensitivities of $5-\mathrm{HT}_{1 \mathrm{~A}}$ and $5-\mathrm{HT}_{2 \mathrm{C}}$ receptors were altered in patients with depressed mood.

A functional approach to biological psychiatry predicts significant associations of biological markers with psychiatric symptoms, such as anxiety, aggression and depressed mood, rather than with psychiatric diagnoses (Van Praag et al. 1987). For the study of biological dysregulations underlying depression this implies that the presence and homogeneity of symptoms in the population studied are more important than the homogeneity of diagnoses. Consequently, in this study patients were selected in whom depressed mood was a core symptom, i.e. they had either a diagnosis of major depression, dysthymia, or anxiety with concomitant depression of mood. Two different 5-HT agonists (m-CPP and ipsapirone) were administered to assess $5-\mathrm{HT}_{1 \mathrm{~A}}$ and $5-\mathrm{HT}_{2 \mathrm{C}}$ receptor sensitivity in patients and control subjects. The purpose of this study was to explore the relationship between depressed mood and specific 5-HT receptor function as measured by: (1) neuroendocrine responses; (2) mood responses; (3) cognitive responses to $\mathrm{m}-\mathrm{CPP}$ and ipsapirone challenge. Elevated hormonal responses to $\mathrm{m}-\mathrm{CPP}$ and blunted hormonal responses to ipsapirone were hypothesized to distinguish patients with depressed mood from controls.

\section{METHODS}

\section{Subjects}

Patients and healthy control subjects were recruited through the University Hospital outpatient clinic and through local newspaper advertisements, respectively. Inclusion criteria were: age between 18 and 65 years, patients suffered from major depression without psychotic features, from dysthymia, or from an anxiety disorder with depressed mood according to DSM IV criteria (APA 1994). In the anxiety group the criterion for depressed mood was a score of at least two points on each of the first two items of the Montgomery Asberg Rating Scale \{MADRS\} (Davidson et al. 1986). After the clinical diagnosis was assessed independently by two clinicians (one psychiatrist in training and a psychiatrist) a SCAN (Structured Clinical Assessment in Neuropsychiatry) (Wing et al. 1990) was performed to confirm the diagnosis. Control subjects were also subjected to a SCAN. All patients were free or washed out from psychotropic medication for at least one week ( 3 months in the case of fluoxetine). Five patients had been on antidepressant medication (four of them on fluoxetine) and had not responded to it satisfactorily. Normal controls were also not allowed to use any regular psychoactive medication. All subjects underwent physical examination and laboratory tests for the routine screening of hematological, biochemical and hormonal blood parameters and standard ECG. Exclusion criteria were: any major medical, endocrine or neurological disease, pregnancy or lactation, alcohol or drug abuse in the past six months, hypertension (diastolic $>100$, systolic $>170$ ). Controls were paid for their participation, patients were only paid if they were not treated at our clinic; travel costs were being paid. The protocol was approved by the medical ethics committee of the University Hospital Maastricht. All subjects had signed voluntary informed consent. 


\section{Experimental Design and Treatments}

The study was conducted according to a mixed between/within-subjects $2 \times 3$ design. The between subjects factor (Group) consisted of two levels (patients vs. control subjects). The within subjects factor (Drug) consisted of three levels (m-CPP $0.5 \mathrm{mg} / \mathrm{kg}$, ipsapirone 10 $\mathrm{mg}$ and placebo) according to a double-blind, placebocontrolled, order-balanced, cross-over design. The three substances were administered as powders, dissolved in a glass of water. The powders were of identical appearance and taste. The test days were spaced minimally four days apart. Mcpp was obtained from Aldrich Chemical Company and ipsapirone was provided by Bayer. Plasma m-CPP determination was performed using highperformance liquid chromatography (HPLC) (Stolk et al. 1997). Plasma ipsapirone determination was undertaken by Tropon, Cologne, Germany using a specific HPLC method.

\section{Hormonal Assessments}

Every $30 \mathrm{~min}$ from $t_{0}$ to $t_{210}\left(x\right.$ in $t_{x}$ denotes minutes after drug administration), blood was taken for the determination of plasma levels of ACTH, cortisol and prolactin.

ACTH has been assayed using a sandwich-type IRMA-method in which the ACTH-molecule is caught in between a first (polyclonal) antibody fixed on a bead and directed versus the C-terminal region and a second monoclonal 125J.-labeled antibody directed versus the $\mathrm{N}$-terminal region of the ACTH-molecule (Nichols Institute Diagnostics,San Juan Capistrano, CA, US). Calibration is based on known amounts of synthetic human ACTH 1-39. The sensitivity of the assay is better than 5 $\mu \mathrm{g} / \mathrm{l}$. Intra- and interassay coefficients of variation are better than $3 \%$ and $6 \%$, respectively. There is an insignificant negative cross-reactivity of the ACTH split products ACTH 1-24 and ACTH $18-39$ of $0.7 \%$ and $0.2 \%$, respectively. This is without any clinical importance.

Cortisol (compound-F) has been analyzed using a solid-phase, chemiluminescent enzyme immunoassay designed to be measured on the Immulite Automated Analyzer (Diagnostic Products Corporation, Los Angeles, USA). Calibration is performed using the standard of the manufacturer. The sensitivity of the assay is about $6 \mathrm{nmol} / 1$. Intra and interassay coefficients of variation are less than $10 \%$. Prednisolone and prednisone show cross-reactivities of .49 and $5.9 \%$, respectively, while the cross reactivity of all other possible interfering substances is less than $0.9 \%$.

The prolactin assay is a solid-phase two site fluoroimmunometric assay designed to be measured on the Autodelfia automatic immunoassay analyser (Perkin Elmer, Wallac, Turku, Finland). The detection with Eu is based on the delayed-enhanced-fluorometric immunoassays (DELFIA) technique. The standards have been calibrated against the $84 / 500$ WHO 3rd International Standard for prolactin. The sensitivity of the assay is better than $0.01(\mathrm{U} / \mathrm{l})$. Intra and interassay coefficients of variation are better than $1 \%$ and $3 \%$, respectively. There is a minor cross reactivity of about $4 \%$ with $\mathrm{hGH}$ and of about $1 \%$ with hPL. Other substances like LH, hCG, FSH and TSH don't show any cross reactivity at all.

\section{Mood Assessments}

Every $30 \mathrm{~min}$ from $\mathrm{t}_{0}$ to $\mathrm{t}_{210}$, subjects were administered the Profile of Mood States Scale (POMS) (McNair et al. 1971). The POMS consists of five separate mood scales (depression, tension, vigor, anger, and fatigue), ranging from 0 to 24 , each based on six items ranging from 0 to 4. Thus, each of these five mood dimensions yielded a score. Furthermore, an overall POMS score, reflecting 'mood level', was constructed by summing the scores for the five subscales, after changing the polarity of the vigor subscale $(y=24-x)$.

\section{Cognitive Assessments}

The cognitive test battery took approximately $30 \mathrm{~min}$ to complete and consisted of tasks measuring visual verbal learning, visual search and motor choice reaction time.

\section{Word Learning Test}

One of twelve parallel lists of 15 monosyllabic meaningful nouns, matched for word frequency, was presented at a rate of $2 \mathrm{~s}$ per word. The subjects were asked to recall verbally as many words as possible as soon as the presentation stopped. This first immediate recall trial was followed by four more trials in which the same words were repeated in the same order. When the fifth trial was completed, the subjects performed the subsequent tasks. After 20 min they were asked to recall as many of the previously learned words as possible without prompting (delayed recall). The number of correctly recalled words was noted after each trial. The trial yielding the maximum number of recalled words was taken as the dependent variable (immediate recall). The delayed recall score was the number of words correctly recalled after $20 \mathrm{~min}$.

\section{Visual Search Signal-Detection Task}

Dots were presented on a computer screen in a random fashion. Every second, two dots changed position. When four dots formed a square, the subject had to push a button as quickly as possible (but within $2 \mathrm{~s}$ ). Efficient and rapid visual search is required to obtain a high signal detection on this task. The reaction time (RT) and the perceptual sensitivity measure (the number of hits corrected for response tendency) were taken as the dependent variable. 


\section{Choice Reaction Time Task}

The subject held one button and was asked to press one of five other buttons located equidistantly from the hold button when lit. This yielded reaction times (RT) consisting of an initiation phase (time from stimulus onset until release of the hold button) and a movement phase (time from release of the hold button until the response button is pushed). The subjects responded either to a single button (simple RT), to one of three buttons which lit up (3-choice RT), or to the right of the lit button (incompatible 3-choice RT) as quickly as possible. This task measures sensorimotor speed, choice-reaction speed, and choice-reaction speed with response competition.

\section{Procedure}

Subjects attended the clinic after an overnight fast. At $\mathrm{t}_{-60}$ an indwelling venous catheter was placed in a forearm vein from which blood was drawn with 30-min intervals until $t_{210}$. Drug administration occurred at 10:00 A.M. $\left(\mathrm{t}_{0}\right)$. Blood samples were placed on ice immediately and were centrifuged at $t_{75}$ and $t_{225}$, and were frozen at $-80^{\circ} \mathrm{C}$ until analysis.

Profile of Mood States was assessed every $30 \mathrm{~min}$ at the same times blood was taken. In between, subjects sat on a bed and were allowed to read magazines. A research nurse was in the room during the entire test. She was instructed to talk only enough so that the subjects would feel at ease but to do administrative work in between the assessments. At $t_{210}$, the subjects were subjected to computerized cognitive tests for half an hour. After the test, the subjects received a meal and went home.

\section{Statistical Analysis}

Hormonal responses were defined as the maximal increase following baseline $\left(t_{0}\right)$ within seven consecutive assessments taken every 30 min from $t_{30}$ to $t_{210}\left(x\right.$ in $t_{x}$ denotes minutes after drug administration). Mood responses were defined in a similar manner using the profile of mood states \{POMS (McNair et al. 1971); 30item dutch validated version\} assessments of the depression, tenseness, fatigue, anger and vigor subscales.

Due to heterogeneity of variance, hormonal and drug data were transformed according to 10-base logarithmic transformation. Hormonal responses were subsequently calculated by taking the peak of the values administered at $t_{30}$ to $t_{210}$ subtracted with the value taken at $t_{0}$.

The effects of $\mathrm{m}-\mathrm{CPP}$, ipsapirone and placebo on hormonal and behavioral responses were evaluated by analysis of variance (ANOVA) according to a mixed between/within subjects repeated measures design. The within subject factor was drug (placebo, m-CPP, ipsapirone) and the between subject factor was group (patients versus controls).

\section{RESULTS}

Fifteen patients and sixteen normal controls completed all experimental sessions. One male patient had dropped out because of severe side effects to m-CPP (Klaassen et al. 1998). The groups did not differ in terms of age, sex, body mass index (BMI) and level of education (see Table 1).

\section{Hormonal Release}

Both drugs elevated hormonal release (Figure 1) of cortisol (drug main effect: $\mathrm{F}=18.0, \mathrm{df}=2,28, p=.000 ; \mathrm{m}-\mathrm{CPP}: \mathrm{F}=$ 35.1, $\mathrm{df}=1,29, p=.000$; ipsapirone: $\mathrm{F}=14.1, \mathrm{df}=1,29$, $p=.001$ ), $\mathrm{ACTH}$ (drug main effect: $\mathrm{F}=12.1, \mathrm{df}=2,28, p=$ $.000 ; \mathrm{m}-\mathrm{CPP}: \mathrm{F}=22.8, \mathrm{df}=1,29, p=.000$; ipsapirone: $\mathrm{F}=$ $13.8, \mathrm{df}=1,29, p=.001$ ) and prolactin (drug main effect: $\mathrm{F}=17.5, \mathrm{df}=2,28, p=.000 ; \mathrm{m}-\mathrm{CPP}: \mathrm{F}=36.1, \mathrm{df}=1,29$, $p=.000$; ipsapirone: $\mathrm{F}=7.4, \mathrm{df}=1,29, p=.011$ ). Patients and controls did not differ in levels of cortisol, ACTH and prolactin measured at $\mathrm{t}_{0}$, prior to drug administration. Cortisol responses to ipsapirone were diminished (blunted) in patients (group X ipsapirone interaction effect: $\mathrm{F}=4.7 \mathrm{df}$ $=1,29, p=.038$ ). ACTH responses to ipsapirone in patients and controls showed a similar but non-significant trend, whereas no differences were observed for ipsapirone-induced prolactin. None of the hormonal responses to $\mathrm{m}-\mathrm{CPP}$ differed between patients and control subjects.

\section{Mood}

POMS ratings (see Figure 2) were significantly higher in patients relative to controls for the items depression $(\mathrm{F}=$ $15.3, \mathrm{df}=1,29, p=.001)$, tenseness $(\mathrm{F}=16.0, \mathrm{df}=1,29$, $p=.000)$, fatigue $(\mathrm{F}=22.2, \mathrm{df}=1,29, p=.000)$ and anger $(\mathrm{F}=6.8, \mathrm{df}=1,29, p=.015)$ and significantly lower for vigor $(\mathrm{F}=53.9, \mathrm{df}=1,29, p=.000)$.

Mcpp increased feelings of depression $(\mathrm{F}=5.1 \mathrm{df}=$ $1,29, p=.012)$, tenseness $(\mathrm{F}=8.7, \mathrm{df}=1,29, p=.006)$ and fatigue $(\mathrm{F}=7.0, \mathrm{df}=1,29, p=.013)$, but not of anger and vigor. Drug-induced worsening of mood was exclusively seen in the patient group after $\mathrm{m}-\mathrm{CPP}$ on the items depres-

Table 1. Means, Standard Errors and Frequencies of Subject Variables

\begin{tabular}{lcr}
\hline & Patients & Controls \\
\hline M/F & $7 / 8$ & $7 / 9$ \\
Age (yrs) & $46.4 \pm 3.0$ & $46.6 \pm 3.3$ \\
Level of education (1-7) & $3.2 \pm 0.6$ & $3.2 \pm 0.4$ \\
BMI (weight/length ${ }^{2}$ ) & $24.3 \pm 0.7$ & $24.1 \pm 0.7$ \\
Major Depressive Disorder (DSM IV & & \\
$\quad$ 296) & 9 & \\
$\begin{array}{l}\text { Dysthymic Disorder (DSM IV 300.4) } \\
\text { Anxiety Disorders + Depressed } \\
\quad \text { Mood }\end{array}$ & 3 & \\
(DSM IV 308.3, 300.1 and 300.02) & 3 & \\
\hline
\end{tabular}



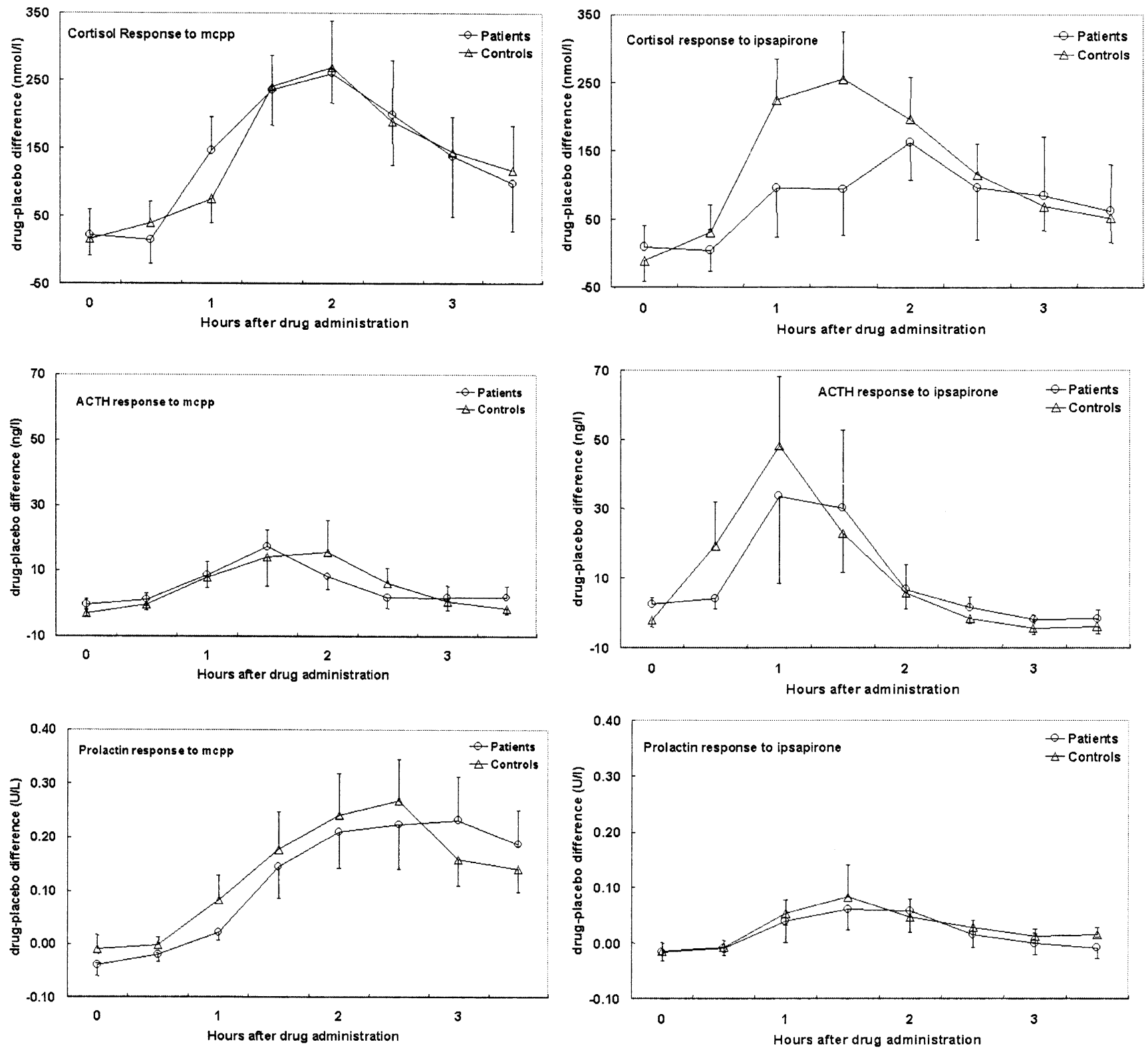

Figure 1. Hormonal responses to 5-HT agonists as a function of time after drug administration broken down by patients with depressed mood $(n=15)$ and healthy control subjects $(n=16)$. The y-axes on the left and right are the same, to enhance comparability between drug effects. The graphs depict drug-placebo difference values of hormonal responses taken at 30min intervals following drug administration at $\mathrm{t}_{0}$ (baseline).

sion $(\mathrm{F}=8.2, \mathrm{df}=1,29, p=.008)$ and tenseness $(\mathrm{F}=5.8$, $\mathrm{df}=1,29, p=.022)$ but not on fatigue, anger and vigor.

Ipsapirone had no significant effect on mood in patients, nor in normal controls.

\section{Cognitive Performance}

Analysis of placebo scores (effect of group) (Table 2) showed that depressed patients performed significantly worse than controls, particularly with respect to learning (immediate recall: $\mathrm{F}=7.3, \mathrm{df}=1,29, p=.012$ ) and memory (delayed recognition sensitivity: $\mathrm{F}=8.1$, $\mathrm{df}=$
$1,29, p=.008$; delayed recognition $\mathrm{RT}: \mathrm{F}=5.8, \mathrm{df}=1,29$, $p=.023)$ and speed of responding to compatible $(\mathrm{F}=$ $4.8, \mathrm{df}=1,29, p=.038)$ and incompatible stimuli $(\mathrm{F}=5.6$, $\mathrm{df}=1,29, p=.025)$ in choice RT.

\section{Word Learning}

There was a significant multivariate interaction effect of Drug X Group ( $\mathrm{F}=3.1, \mathrm{df}=2,28, p=.05)$ indicating different effects of the drugs on immediate recall in patients versus control subjects. Univariate comparisons showed an interaction effect of Ipsapirone X Group ( $\mathrm{F}=$ 

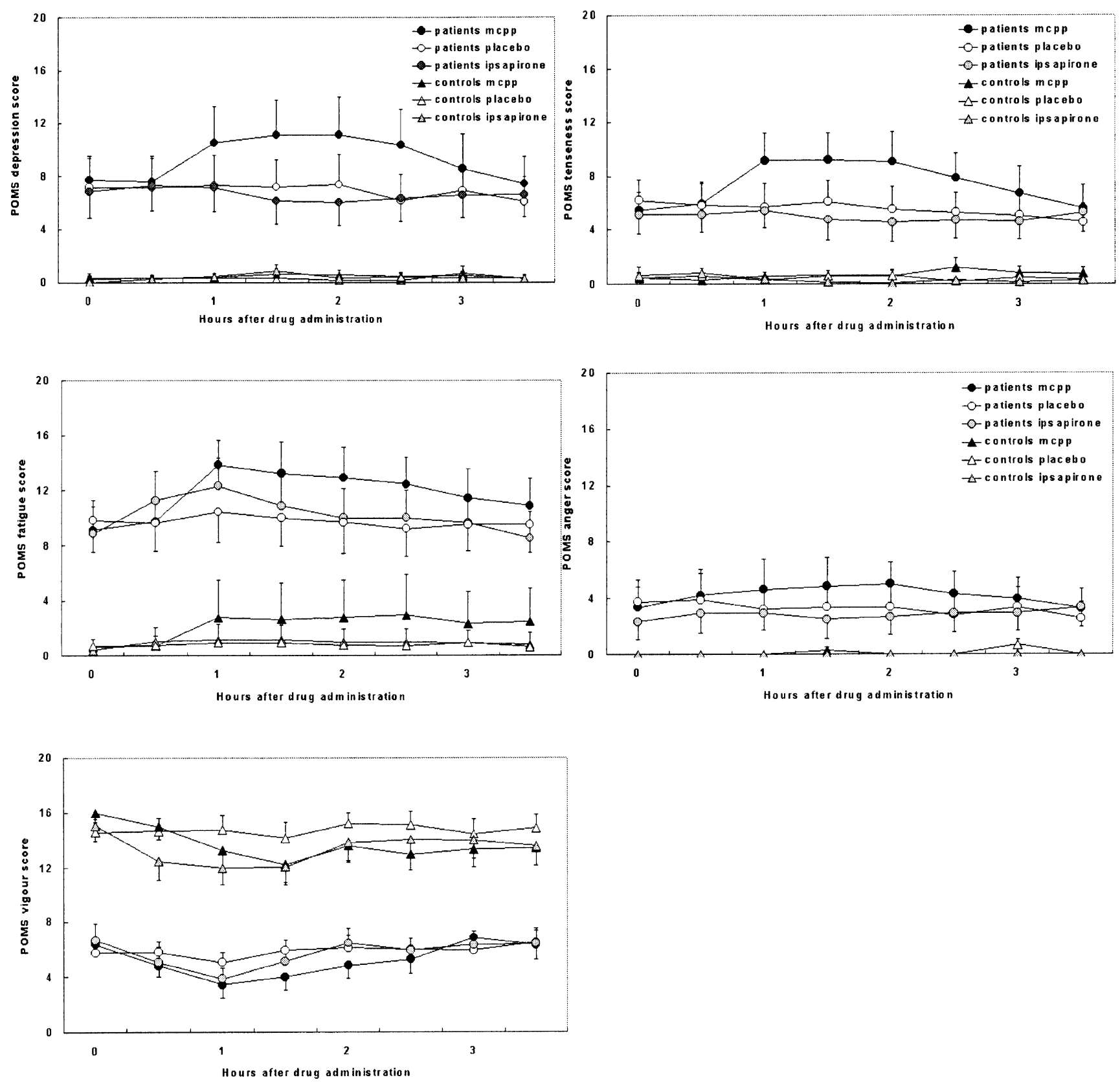

Figure 2. Mood responses to 5-HT agonists as a function of time after drug administration broken down by patients with affective disorders $(n=15)$ vs. healthy control subjects $(n=16)$ and drug treatment conditions. The graphs depict scores on the profile of mood states (POMS) subscales of depression (top left), tenseness (top right), fatigue (midle left), anger (middle right) and vigor (bottom left).

$6.4, \mathrm{df}=1,29, p=.017)$ indicating that ipsapirone improved immediate recall in patients and impaired immediate recall in control subjects.

\section{Visual Search}

$\mathrm{m}$-CPP impaired signal detection efficiency in controls and not in patients. The multivariate Drug $X$ Group interaction effect was significant $(\mathrm{F}=7.3 \mathrm{df}=2,28, p=.003)$ and so was the univariate interaction effect for $\mathrm{m}-\mathrm{CPP} X$ Group
$(\mathrm{F}=14.1, \mathrm{df}=1,29, p=.001)$. The main effect of $\mathrm{m}-\mathrm{CPP}$ was also significant $(\mathrm{F}=5.3, \mathrm{df}=1,29, p=.029)$, but inspection of the data showed that this was entirely due to the interaction effect. There were no effects on signal detection RT. There were no effects of ipsapirone on visual search.

\section{Choice RT}

Irrespective of group, $\mathrm{m}$-CPP significantly impaired simple $\mathrm{RT}(\mathrm{F}=4.7, \mathrm{df}=1,29, p=.040)$, compatible choice RT ( $\mathrm{F}=$ 
Table 2. Means and Standard Errors of Dependent Measures Broken Down by Subject Groups and Drug Treatment

\begin{tabular}{|c|c|c|c|c|c|c|}
\hline & \multicolumn{3}{|c|}{ Patients } & \multicolumn{3}{|c|}{ Controls } \\
\hline & ipsapiron & mcpp & placebo & ipsapiron & mcpp & placebo \\
\hline \multicolumn{7}{|l|}{ Word Learning } \\
\hline Max. Imm. Rec. (0-15) & $11.1 \pm 0.6$ & $10.7 \pm 0.7$ & $10.6 \pm 0.8$ & $10.9 \pm 0.6$ & $11.3 \pm 0.4$ & $12.7 \pm 0.3$ \\
\hline Delayed Recall (0-15) & $8.5 \pm 0.8$ & $9.1 \pm 0.7$ & $7.8 \pm 1$ & $9.6 \pm 0.6$ & $9.4 \pm 0.6$ & $9.7 \pm 0.5$ \\
\hline Recogn. Sens. (\%) & $91 \pm 1$ & $91 \pm 1$ & $89 \pm 3$ & $96 \pm 1$ & $95 \pm 1$ & $94 \pm 1$ \\
\hline Recogn. RT & $792 \pm 30$ & $739 \pm 26$ & $766 \pm 27$ & $656 \pm 24$ & $684 \pm 19$ & $690 \pm 31$ \\
\hline \multicolumn{7}{|l|}{ Visual Search } \\
\hline Sign. Det. Sens. & $69 \pm 3$ & $69 \pm 3$ & $66 \pm 4$ & $73 \pm 3$ & $66 \pm 3$ & $75 \pm 3$ \\
\hline Sign. Det. RT & $913 \pm 41$ & $901 \pm 38$ & $866 \pm 37$ & $827 \pm 27$ & $863 \pm 36$ & $807 \pm 20$ \\
\hline \multicolumn{7}{|l|}{ Motor Choice RT } \\
\hline Mov. Time (msec) & $139 \pm 10$ & $140 \pm 9$ & $147 \pm 11$ & $135 \pm 7$ & $133 \pm 9$ & $135 \pm 8$ \\
\hline Simple RT (msec) & $323 \pm 9$ & $351 \pm 16$ & $328 \pm 11$ & $320 \pm 8$ & $318 \pm 8$ & $310 \pm 8$ \\
\hline Choice RT (msec) & $377 \pm 10$ & $390 \pm 14$ & $375 \pm 9$ & $357 \pm 6$ & $366 \pm 6$ & $352 \pm 7$ \\
\hline S-R inc. RT (msec) & $487 \pm 12$ & $501 \pm 17$ & $478 \pm 14$ & $430 \pm 9$ & $461 \pm 12$ & $436 \pm 11$ \\
\hline
\end{tabular}

$4.7, \mathrm{df}=1,29, p=.038)$ and incompatible choice $\mathrm{RT}(\mathrm{F}=4.7$, $\mathrm{df}=1,29, p=.039)$. There were no effects on movement time. There were no effects of ipsapirone on choice RT.

\section{Gender Differences}

A rerun of all analyses with the inclusion of the factor Gender did not show any difference in cognitive performance between males and females in either of the patient and control groups. Furthermore, the drug effects hitherto reported did not seem to differ between male and female patients or controls.

\section{Effects of Age, Education and BMI}

Correlational analyses of age, education and BMI with hormonal and mood responses, defined as drug-placebo difference scores, showed that within the patient group $\mathrm{m}-\mathrm{CPP}$-induced elevations of depression $(\mathrm{r}=$ $.62, \mathrm{n}=15, p=.014)$, tenseness $(\mathrm{r}=.28, \mathrm{n}=15, p=$ $.023)$ and anger $(\mathrm{r}=.53 \mathrm{df}=15, p=.042)$ were positively associated with level of education. There were no associations of drug-induced hormonal and mood responses with age and BMI.

\section{Intercorrelations of Hormonal with Mood Responses}

Correlational analyses of hormonal responses to m-CPP and ipsapirone, expressed as drug-placebo difference scores, with similarly expressed POMS-derived mood responses revealed that within the patient group there were positive associations of the $\mathrm{m}-\mathrm{CPP}$-induced prolactin response with the $\mathrm{m}-\mathrm{CPP}$-induced elevations of depression $(\mathrm{r}=.57, \mathrm{n}=15, p=.028)$ and tenseness $(\mathrm{r}=$ $.52, \mathrm{n}=15, p=.047)$. There were no indications of a statistical association within the patient group between the ipsapirone-induced blunting of cortisol response and the m-CPP-induced worsening of mood.

\section{Blood Levels of m-CPP and ipsapirone}

m-CPP and ipsapirone blood levels did not differ significantly between patients and control subjects (see Figure 3). $m-C P P$ had its mean peak level at $t_{120}$, while the mean ipsapirone peak level was already obtained at $t_{30}$.

\section{Effects of Diagnostic Groups}

Re-analysis of the data was performed, now incorporating the diagnostic groups into a between groups factor with four levels: major depression $(\mathrm{n}=9)$, dysthymia $(n=3)$, anxiety + depression $(n=3)$, controls $(n=16)$. In brief, what descriptive statistics showed was that the blunted cortisol response to ipsapirone was not observed in anxiety disorder patients with depressed mood. No other findings emerged from this exercise. Between groups statistical tests of significance to substantiate this observation would go below the statistically acceptable level of at least four observations per cell. Therefore, a way to substantiate this finding was to redo the analyses with the three anxiety+depression patients excluded. The ipsapirone-induced blunted cortisol response in the remaining 12 patients vs. 16 controls appeared to be a more robust effect without the three anxiety + depression patients (group $X$ ipsapirone interaction effect: $\mathrm{F}=5.5, \mathrm{df}=1,26, p=.027)$.

\section{DISCUSSION}

To the best of our knowledge, this is the first neuroendocrine challenge study in patients with depressed mood, in which two 5-HT receptor types were studied. 

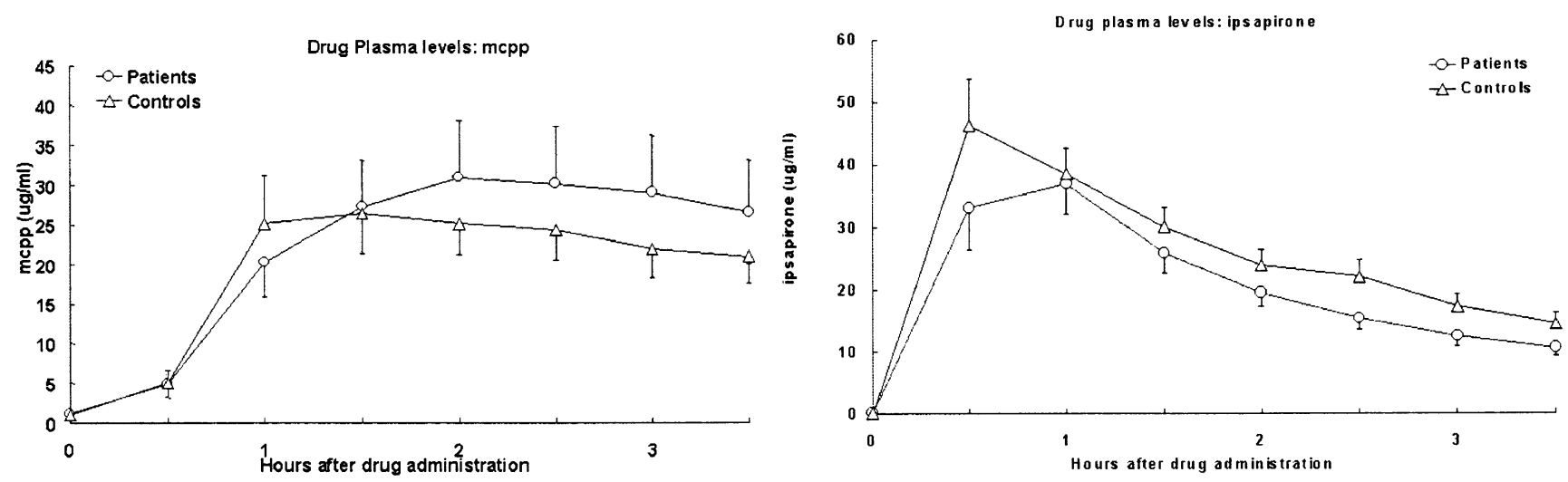

Figure 3. Plasma levels of m-CPP (mcpp, left) and ipsapirone (right) as a function of time after drug administration broken down by patients with affective disorders $(n=15)$ vs. healthy control subjects $(n=16)$.

Drug effects on hormonal secretion can be summarized as robust $\mathrm{m}-\mathrm{CPP}$-induced elevations of cortisol, prolactin and $\mathrm{ACTH}$, whereas ipsapirone produced robust elevations of cortisol and ACTH and somewhat less of prolactin. Drug effects on mood can be summarized as $\mathrm{m}$-CPP-induced elevation of depression and tenseness in patients and an overall $\mathrm{m}$-CPP-induced increase of fatigue. A blunted cortisol response to ipsapirone was seen in patients with depressed mood compared with controls. An exaggerated mood response to $\mathrm{m}-\mathrm{CPP}$ was seen in patients compared with controls. Another significant ipsapirone-induced difference between groups was the impairment of memory performance in controls and improvement in patients. These findings are in agreement with previous separate studies that showed a blunted cortisol response to ipsapirone in depressed patients (Lesch et al. 1990; Meltzer and Maes 1995) and hyperresponsivity to m-CPP in terms of subjective mood (Charney et al. 1987; Kahn and Wetzler 1991; Lawlor et al. 1989). Our strategy, the so-called functional approach, was based on the inclusion of patients with depressed moods on the basis of symptoms rather than diagnostic categories. However, in anxiety patients with depressed moods, we did not observe the blunted cortisol response to ipsapirone that we saw in patients with depression and dysthymia.

Stahl (1998) distinguishes five pathways in which serotonergic drugs generally manifest their actions. He describes serotonergic projections to the frontal cortex, the basal ganglia, hippocampus, hypothalamus and to the spinal cord (Stahl 1998). The effects of $m-C P P$ and ipsapirone most probably reflect different expressions of serotonergic modulation in hypothalamic (hormonal), amygdalo-frontal (mood) and hippocampal (memory) pathways, although it must be noted here that these associations are only well established in the case of endocrine effects mediated via serotonergic modulation of the hypothalamus.
Even though hormonal responses to $\mathrm{m}-\mathrm{CPP}$ did not differ in our study, the observed pattern of subjective responses could be taken as an indication of hypersensitivity of fronto-cortical $5-\mathrm{HT}_{2}$ receptors (where these receptors are most abundant), in depressed patients relative to normal control subjects. This is in contrast to the blunted cortisol response to ipsapirone in patients with depressed mood, which can be taken as a sign of diminished hypothalamic postsynaptic $5-\mathrm{HT}_{1 \mathrm{~A}}$ receptor sensitivity. Similarly but more speculatively, the differential effects of ipsapirone on memory in patients and controls could reflect altered hippocampal $5-\mathrm{HT}_{1 \mathrm{~A}}$ receptor sensitivity in a manner such that the stimulation of these receptors is positively associated with memory performance, only if these receptors are desensitized, e.g. due to long-term repeated overstimulation with cortisol. The latter would also explain the decreased memory performance seen in patients with depressed mood (McAllister-Williams et al. 1998).

An alternative explanation might be that memory effects are due to agonistic and antagonistic actions of ipsapirone in patients and controls, respectively. This putative differential pharmacological effect might be explained by the partial agonistic property of ipsapirone.

A different explanation may be that low 5-HT has been shown to induce long-term depression (LTD), as opposed to long-term potentiation (LTP) of synaptic plasticity, especially in hippocampal area, possibly through modulation of calcium $(2+)$ channels, through which 5-HT has been shown to normally inhibit LTD (Normann 2000; Normann et al. 2000). This mechanism may account for positive effects of 5-HT in patients and may also explain tryptophan-depletion induced memory consolidation impairment and mood lowering in normal subjects (Riedel et al. 1999).

In contrast to a previous study in which no cognitive effects of m-CPP were reported (Silverstone et al. 1994), we found impaired performance after $\mathrm{m}-\mathrm{CPP}$ on all Re- 
action Time tasks. However, we assessed performance $3.5 \mathrm{~h}$ after administration whereas the previously mentioned study, performance was assessed 1-2 $\mathrm{h}$ after administration. If $\mathrm{m}-\mathrm{CPP}$ would be considered having stimulant properties, these observations might fit the pattern of initial activation, or CNS disinhibition, followed by withdrawal or deactivation, leading to a slowing of RT (Gijsman et al. 1998).

We conclude that in patients with major depression and dysthymia, hypothalamic and possibly also hippocampal 5- $\mathrm{HT}_{1 \mathrm{~A}}$ desensitisation and non-hypothalamic $5-\mathrm{HT}_{2 \mathrm{C}}$ sensitisation, probably fronto-cortical, mediate depressed mood along with impaired memory performance.

\section{ACKNOWLEDGMENTS}

This study was made possible by a grant from the Maastricht University's Hospital Clinical Research Fund ("Profileringsfonds"). We thank Bayer for their supplying of ipsapirone and the determination of ipsapirone plasma levels. Our thanks also go to Prof. Michael Maes for reviewing the manuscript.

\section{REFERENCES}

APA (1994): Diagnostic and Statistical Manual of Mental Disorders, Fourth Edition. Washington, DC, American Psychiatric Association

Broocks A, Bandelow B, George A, Jestrabeck C, Opitz M, Bartmann U, Gleiter CH, Meineke I, Roed IS, Ruther E, Hajak G (2000): Increased psychological responses and divergent neuroendocrine responses to $\mathrm{m}-\mathrm{CPP}$ and ipsapirone in patients with panic disorder. Int Clin Psychopharmacol 15:153-161

Broocks A, Meyer T, George A, Hillmer-Vogel U, Meyer D, Bandelow B, Hajak G, Bartmann U, Gleiter CH, Ruther E (1999): Decreased neuroendocrine responses to metachlorophenylpiperazine (m-CPP) but normal responses to ipsapirone in marathon runners. Neuropsychopharmacology 20:150-161

Charney DS, Woods SW, Goodman WK, Heninger GR (1987): Serotonin function in anxiety II. Effects of the serotonin agonist mcpp in panic disorder patients and healthy subjects. Psychopharmacology 92:14-24

Davidson J, Turnbull CD, Strickland R, Miller R, Graves K (1986): The Montgomery-Asberg Depression Scale: reliability and validity. Acta Psychiatr Scand 73:544-548

De Vry J (1995): 5-HT(1A) receptor agonists: Recent developments and controversial issues. Psychopharmacology 121:1-26

Gijsman HJ, Van Gerven JM, Tieleman MC, Schoemaker RC, Pieters MS, Ferrari MD, Cohen AF, Van Kempen GM (1998): Pharmacokinetic and pharmacodynamic profile of oral and intravenous meta-chlorophenylpiperazine in healthy volunteers. J Clin Psychopharmacol 18:289295

Glennon RA, Ismael A, McCarthy BJ, Peroutka SJ (1989):
Binding of arylpiperazines to $5-\mathrm{HT} 3$ receptors. Results of a structure-affinity study. Europ J Pharmacol 168:3 87-392

Hamik A, Peroutka SJ (1989): 1-(m-Chlorophenyl)piperazine $(\mathrm{mCPP})$ interactions with neurotransmitter receptors in the human brain. Biol Psychiatry 25:569-575

Hoyer D (1988): Functional correlates of serotonin 5-HT1 recognition sites. J Receptor Res 8:59-81

Kahn RS, Wetzler S (1991): m-Chlorophenylpiperazine as a probe of serotonin function. Biol Psychiatry 30:11391166

Kahn RS, Wetzler S, Asnis GM, Kling MA, Suckow RF, Van Praag HM (1991): Pituitary hormone responses to metachlorophenylpiperazine in panic disorder and healthy control subjects. Psychiatry Res 37:25-34

Kahn RS, Wetzler S, Van Praag HM, Asnis GM (1988a): Behavioral indications for serotonin receptor hypersensitivity in panic disorder. Psychiatry Research 25:101-104

Kahn RS, Wetzler S, Van Praag HM, Asnis GM (1988b): Neuroendocrine evidence for 5-HT receptor hypersensitivity in patients with panic disorder. Psychopharmacology 96:360-364

Klaassen T, Hott Pian K, Westenberg HGM, Den Boer JA, Van Praag HM (1998): Serotonin syndrome after challenge with the 5-HT agonist meta-chlorophenylpiperazine. Psychiatry Research 79:207-212

Lawlor BA, Sunderland T, Mellow AM, Hill JL, Molchan SE, Murphy DL (1989): Hyperresponsivity to the serotonin agonist m-chlorophenylpiperazine in Alzheimer's disease. A controlled study. Arch Gen Psychiatry 46:542-549

Lesch KP, Sohnle K, Poten B, Schoellnhammer G, Rupprecht R, Schulte HM (1990): Corticotropin and cortisol secretion after central 5-hydroxytryptamine-1A (5-HT1A) receptor activation: effects of 5-HT receptor and betaadrenoceptor antagonists. J Clin Endocrinol Metab 70: 670-674

Maes M, Meltzer HY (1995): The Serotonin Hypothesis of Major Depression. In Bloom FE, Kupfer DJ (eds), Psychopharmacology: The Fourth Generation of Progress. New York, Raven Press, pp 933-944

Maes M, Meltzer HY, D’Hondt P, Cosyns P, Blockx P (1995): Effects of serotonin precursors on the negative feedback effects of glucocorticoids on hypothalamic-pituitaryadrenal axis function in depression. Psychoneuroendocrinology 20:149-167

McAllister-Williams RH, Ferrier IN, Young AH (1998): Mood and neuropsychological function in depression: the role of corticosteroids and serotonin. Psychological Medicine 28:573-584

McNair DM, Lorr M, Droppleman LF (1971): Manual for the Profile of Mood States. San Diego, Educational and Industrial Testing Service

Meltzer HY, Maes M (1995): Effects of ipsapirone on plasma cortisol and body temperature in major depression. Biol Psychiatry 38:450-457

Meltzer HY, Umberkoman-Wiita B, Robertson A, Tricou BJ, Lowy M, Perline R (1984): Effect of 5-hydroxytryptophan on serum cortisol levels in major affective disorders. I. Enhanced response in depression and mania. Arch Gen Psychiatry 41:366-374 
Normann C (2000): Towards a new model for cellular pathophysiology in affective disorder. Acta Neuropsychiatrica 12:77-80

Normann C, Peckys D, Schulze CH, Walden J, Jonas P, Bischofberger J (2000): Associative long-term depression in the hippocampus is dependent on postsynaptic N-type Ca2+ channels. J Neurosci 20:8290-8297

Peroutka SJ (1988): 5-Hydroxytryptamine receptor subtypes: Molecular, biochemical and physiological caracterization. Trends Neurosci 11:496-500

Riedel WJ, Klaassen T, Deutz NEP, Van Someren A, Van Praag HM (1999): Tryptophan Depletion in Normal Volunteers Produces Selective Impairment in Memory Consolidation. Psychopharmacology 141:362-369

Silverstone PH, Rue JE, Franklin M, Hallis K, Camplin G, Laver D, Cowen PJ (1994): The effects of administration of $\mathrm{mCPP}$ on psychological, cognitive, cardiovascular, hormonal and MHPG measurements in human volunteers. Int Clin Psychopharmacol 9:173-178

Stahl SM (1998): Mechanism of action of serotonin selective reuptake inhibitors. Serotonin receptors and pathways mediate therapeutic effects and side effects. J Affect Disord 51:215-235

Stolk LML, Groothuijsen H, Hoogtanders K (1997): A semiautomated sensitive HPLC method for detemination of $\mathrm{m}$-chlorophenylpiperazine in plasma. Ther Drug Monit 19:S588

Van Praag HM (1996): Serotonin related, anxiety/aggression driven, stressor precipitated depression: a psycho biological hypothesis. European Psychiatry 11:57-67

Van Praag HM, Kahn RS, Asnis GM, Wetzler S, Brown SL, Bleich A, Korn ML (1987): Denosologization of biological psychiatry or the specificity of 5-HT disturbances in psychiatric disorders. J Affect Disord 13:1-8

Wing JK, Babor T, Brugha T, Burke J, Cooper JE, Giel R, Jablenski A, Regier D, Sartorius N (1990): SCAN, Schedules for clinical Assessment in Neuropsychiatry. Archives of General Psychiatry 47:589-593

Yatham LN, Steiner M (1993): Neuroendocrine probes of serotonergic function: a critical review. Life Sci 53:447-463 